Original Research Article

\title{
Analysis of the pattern of ADR's reported to an ADR monitoring center in South India: a prospective study
}

\author{
Anant Khot ${ }^{1 *}$, Thresiamma K. Thomas ${ }^{2}$, Savithri P. ${ }^{2}$, Rajalakshmi A. N. ${ }^{2}$
}

${ }^{1}$ Department of Pharmacology, BLDEU's SBMPMC,

Vijayapur, Karnataka, India

${ }^{2}$ Department of Pharmacology,

Amrita Institute of Medical

Science, Kochi, India

Received: 04 August 2017

Revised: 18 August 2017

Accepted: 29 August 2017

\section{*Correspondence to:}

Dr. Anant Khot,

Email: anantkhot04@gmail.com

Copyright: (C) the author(s), publisher and licensee Medip Academy. This is an openaccess article distributed under the terms of the Creative Commons Attribution NonCommercial License, which permits unrestricted noncommercial use, distribution, and reproduction in any medium, provided the original work is properly cited.

\begin{abstract}
Background: All medicines with an ability to produce a desired therapeutic effect will also have the potential to cause unwanted adverse effects. It has been established that $\sim 2.9 \%-5.6 \%$ of all hospital admissions are caused by Adverse drug reactions (ADRs) \& as many as $35 \%$ of the hospitalized patients experience an ADR during their hospital stay. An incidence of fatal ADRs is $0.23 \%-0.41 \%$. In some countries, ADRs rank among the top 10 leading causes of mortality. In order to increase awareness, observe the pattern of ADRs and communicate scientific data to prevent ADRs, this study was undertaken.

Methods: It was a prospective observational study conducted at a tertiary hospital in Kochi. All the spontaneously reported ADRs were assessed and analyzed for type, severity and causality.

Results: A total of 120 ADRs were reported during the study period. Most of the ADRs were seen in females in the age group of 61-70 years. Skin and appendage disorders were the most common manifestation of different type of ADRs (49.2\%). Antineoplastic and immunomodulating agents $(30.8 \%)$, followed by anti-infectives for systemic use $(29.2 \%)$ were mostly implicated in the causation of ADRs. Majority of the ADRs were of mild to moderate in severity (89.2\%).

Conclusions: Although small, but significant number of patients had severe ADRs. Hence, we require a robust system for monitoring the medication use process. So that we can prevent and reduce the morbidity and mortality due to therapeutic agents.
\end{abstract}

Keywords: Adverse drug reaction, Antineoplastic agents, Morbidity, Hospitalization

\section{INTRODUCTION}

World Health Organization (WHO) defines an adverse drug reaction (ADR) as, "a response to a drug that is noxious and unintended and occurs at doses normally used in man for the prophylaxis, diagnosis or therapy of disease, or for modification of physiological function". ${ }^{1}$ It has been estimated that approximately $2.9 \%-5.6 \%$ of all hospital admissions are caused by ADRs and as many as $35 \%$ of the hospitalized patients experience an ADR during their hospital stay. An incidence of fatal ADRs is $0.23 \%-0.41 \%$. In some countries, ADRs rank among the top 10 leading causes of mortality. According to the Centre for Health
Policy Research, more than 50 percent of the approved drugs in the United States were associated with some type of adverse effect not detected prior to approval. ${ }^{2}$ A study in South India showed that ADRs accounted for $0.7 \%$ of total admissions and $1.8 \%$ resulted in death. ADRs will increase not only morbidity and mortality, but also add to the overall healthcare cost. The average cost of managing an ADR at the hospital was found to be 481 rupees (£6). ${ }^{3}$

In order to prevent or reduce the harm to patients and to improve public health, mechanisms for evaluating and monitoring the safety of medicines in clinical use are vital. In practice, this means having in place a well-organized pharmacovigilance system. WHO defines 
pharmacovigilance as, "the science and activities relating to the detection, assessment, understanding and prevention of adverse effects or any other medicine-related problem". ${ }^{4}$ India also has a system to monitor ADRs, which is Pharmacovigilance program of India (PvPI) with its center at Indian Pharmacopoeia Commission (IPC) Ghaziabad. Recently, the concerns of Pharmacovigilance have been widened to include herbal, traditional and complementary medicines, blood and blood products, biologicals, medical devices and vaccines. Despite of vigorous effort from IPC, under reporting is widespread and a daunting challenge in pharmacovigilance. In order to create awareness, observe the pattern of ADRs and communicate scientific data to prevent ADRs, this study was undertaken.

\section{METHODS}

This study was conducted at Amrita Institute of Medical Sciences (AIMS), which is an ADR monitoring center (AMC) under PvPI.

Study design was prospective observational study.

\section{Study method}

Initially, staff nurses were oriented towards reporting of ADRs by conducting training programs, displaying poster on the nursing station notice board and by sending e-mails to all health care professionals. Then, they (Nurses, doctors and pharmacists) used to call and inform details of the patient and drug. The deputy coordinator and other people from the department of pharmacology used to visit and collect information from patient and case records. The missing patient information if any was completed by using electronic patient database (Amrita HIS). After collecting the information, they (ADRs) were assessed for causality by using WHO-UMC (World Health OrganizationUppsala Monitoring Centre) causality assessment system. ${ }^{5}$ The severity of an ADR was assessed by using the criterion developed by Hartwig et. al. ${ }^{6}$ After the assessment, it was entered in to Vigiflow software and the Portable Document Format (PDF) generated after uploading it was used for data stratification based on Medical Dictionary for Regulatory Activities (MedDRA) for adverse event/adverse drug reaction and Anatomical Therapeutic Chemical (ATC) classification system was used to classify drugs implicated in causing an ADR. ${ }^{7,8}$ The study was approved by Institutional ethics committee and permission from medical superintendent was sought before using hospital data.

Study period was from April 2014 to May 2015.

\section{RESULTS}

A total of 120 ADRs were reported during study period. Among 120 cases, 57 patients had Type A and 63 patients had Type B ADRs according to Rawlins and Thompson classification.
Table 1: Demographic characteristics.

\begin{tabular}{|lll|}
\hline Sex & $\begin{array}{l}\text { Male patients - } \\
\mathbf{5 5}(\mathbf{4 5 . 8 \% )}\end{array}$ & $\begin{array}{l}\text { Female- 65 } \\
\mathbf{( 5 4 . 2 \% )}\end{array}$ \\
\cline { 1 - 2 } Type of reaction & Type A-57 & Type B-63 \\
\cline { 1 - 2 } Reporter & $\begin{array}{l}\text { Number of cases } \\
\text { reported (N=120) }\end{array}$ & \\
\cline { 1 - 2 } Doctors & $53(44.2 \%)$ & \\
\cline { 1 - 2 } Pharmacists & $39(32.5 \%)$ & \\
\cline { 1 - 2 } Nurses & $28(23.3 \%)$ & \\
\hline
\end{tabular}

Table 1 shows the demographic characteristics of patients and cadre of health care professionals who reported ADRs. Minimum age at which patient suffered an ADR was 1 year and maximum age was 79 yrs. Age range at which maximum ADRs were seen was between 61-70 years as shown in Figure 1.

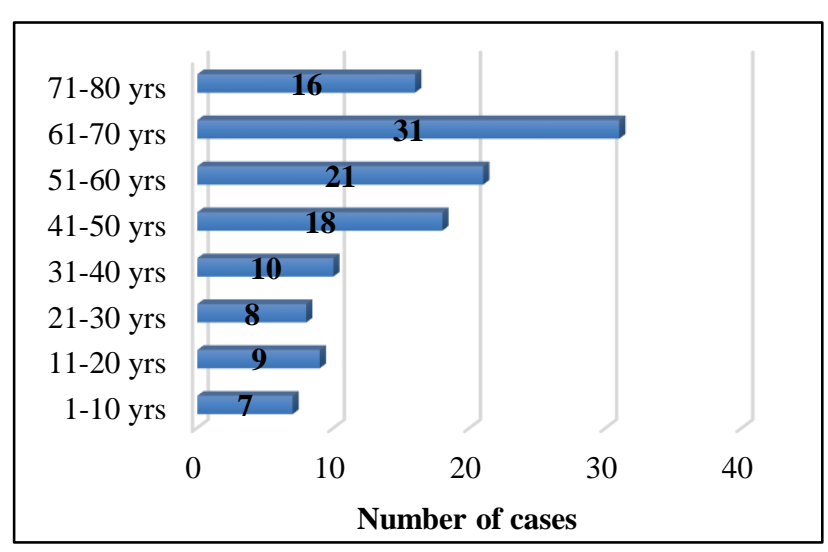

Figure 1: The distribution of ADRs according to the age range.

Skin and appendage disorders were the commonest manifestations of different types of ADRs -59 cases (49.2\%), followed by immune system disorders- 15 cases (12.5\%). Remaining ADR's with its SOC have been shown in Figure 2.

Antineoplastic and immunomodulating agents -37 cases $(30.8 \%)$, followed by anti-infectives for systemic use -35 cases $(29.2 \%)$ were predominantly involved in causation of ADR's as shown in Figure 3.

Table 2: The outcome of ADRs reported.

\begin{tabular}{|lll|}
\hline Outcome & Frequency & Percentage \\
\hline Fatal & 1 & 0.8 \\
\hline Recovering & 24 & 20 \\
\hline Continuing & 2 & 1.7 \\
\hline Recovered & 79 & 65.8 \\
\hline Unknown & 10 & 8.3 \\
\hline Others & 4 & 3.3 \\
\hline Total & 120 & 100 \\
\hline
\end{tabular}

Figure 4 shows the causality assessment according to the WHO-UMC scale. According to that, 75.8\% ADR's were 
categorized as possible, $22.5 \%$ as probable and $1.7 \%$ as certain.

79 patients recovered either spontaneously or with symptomatic treatment. 1 death was reported during this period for which levofloxacin induced seizures could have contributed in the elderly aged 76 years. The outcome of remaining cases was as shown in Table 2.

According to the modified Hartwig and Siegel scale, most of the ADRs were of mild to moderate severity. Among 120 cases reviewed, only 13 cases were severe and which required intensive care.

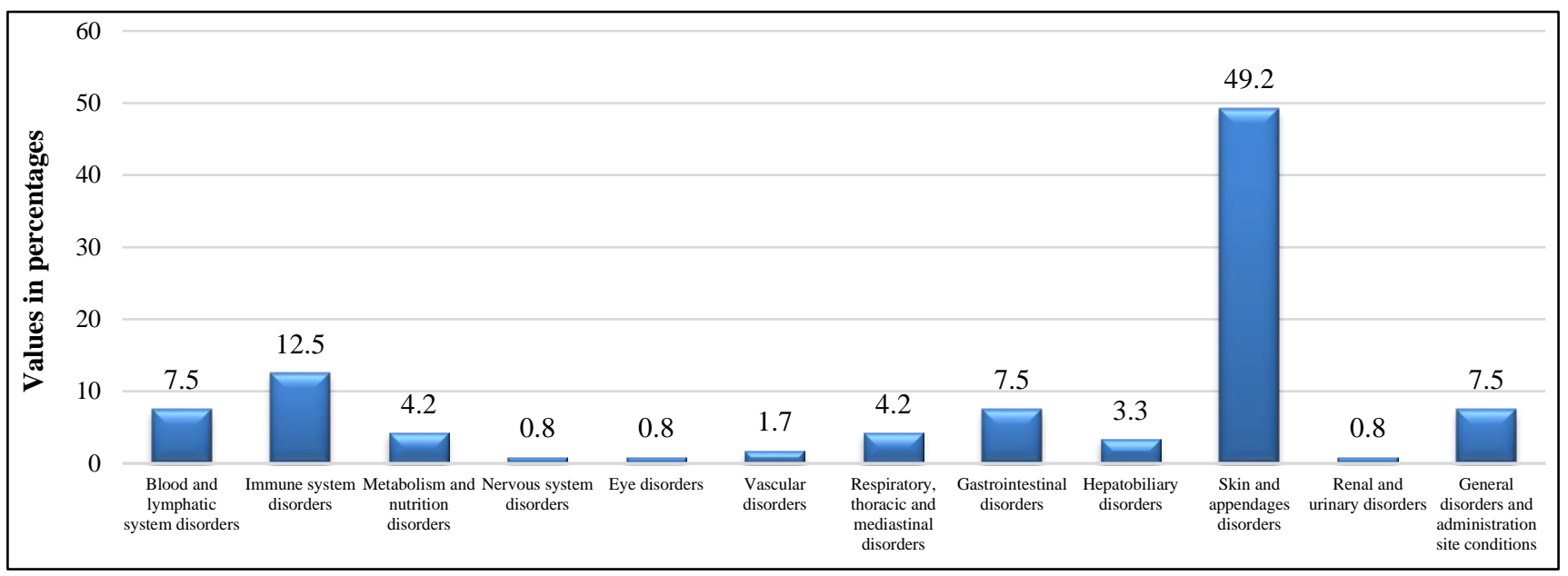

Figure 2: The distribution of ADR's according to the SOC in MedDRA.

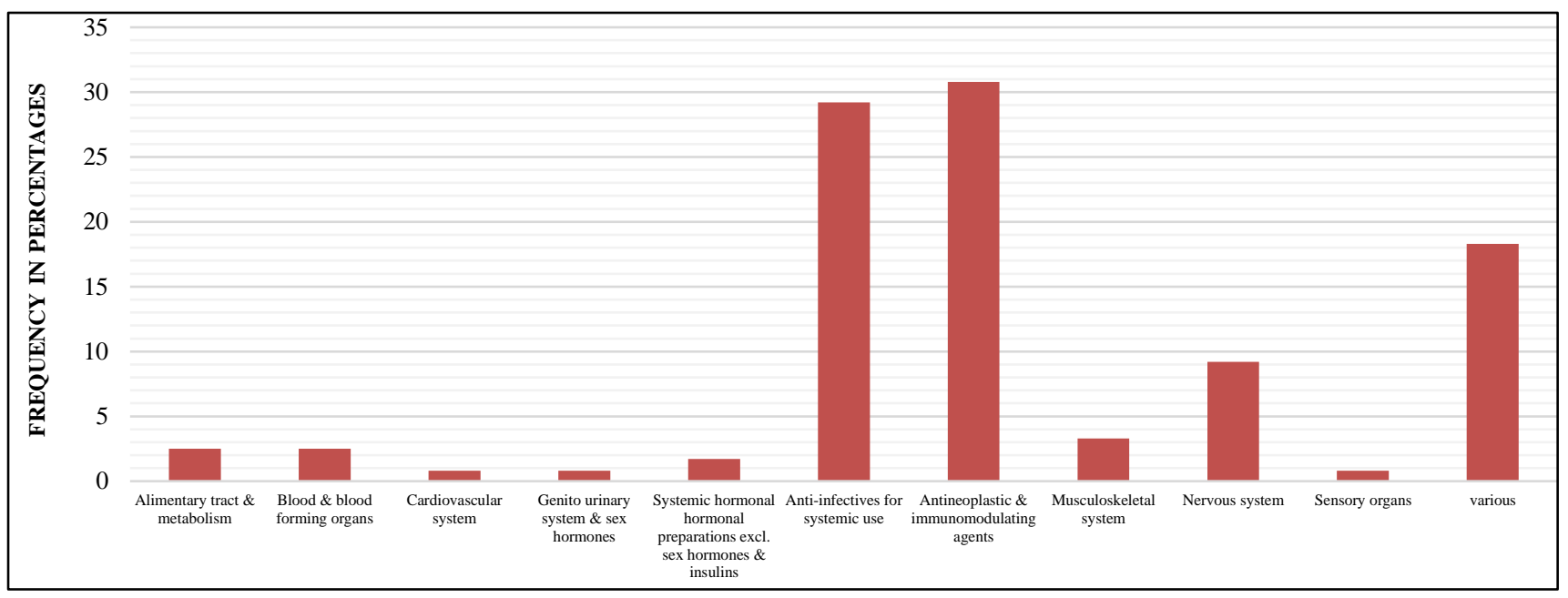

Figure 3: Depicts the ATC class of drugs involved in the causation of ADR's.

\section{Statistical analysis}

Data was analyzed by using SPSS 23, IBM obtained from SPSS South Asia Private limited, Bangalore, India. Microsoft excel 2016 was used to design graph and pie charts.

\section{DISCUSSION}

The results of our study show that, it is skin and appendage disorders -are the commonest manifestation of different types of ADRs (49.2\%). Cutaneous reactions ranged from simple rash and itching to severe form such as Stevens Johnson syndrome (Allopurinol induced). ADRs occurred predominantly in females in the age group of 61-70 yrs, may be due to age related changes in pharmacokinetic parameters or pharmacodynamic response to drugs, comorbid illnesses and also polypharmacy.

Most of the ADRs were mild to moderate in severity and majority of them have recovered with or without symptomatic treatment. Majority of the ADRs were spontaneously reported by Doctors, Pharmacists as compared to nursing staff. A predominant class of drugs that are suspected in the causation of ADR's were 
antineoplastic and immunomodulating agents followed by anti-infective drugs for systemic use. The findings of our study are consistent with the study carried out by Halkai K et al, and Sutradhar SD et al, Skewed from the data published by Yadav D et al..$^{9-11}$

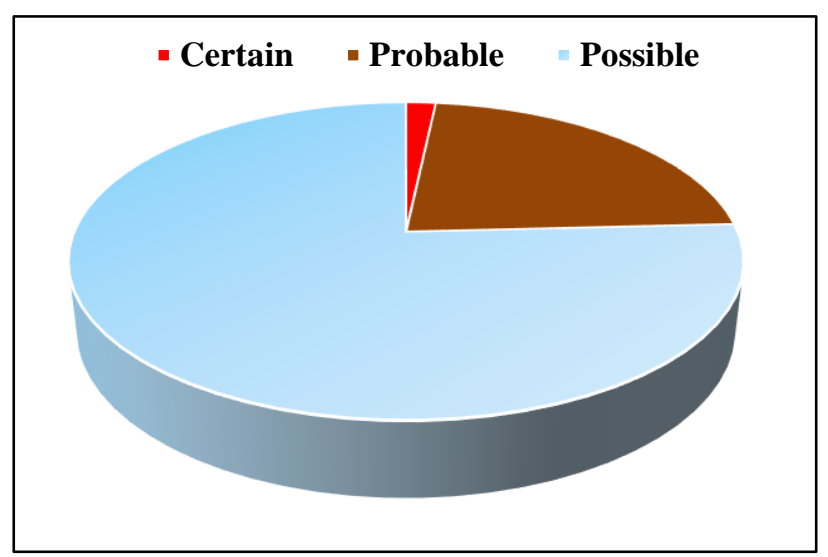

Figure 4: Causality assessment according to the WHO-UMC scale.

According to them Gastrointestinal system disorders were the predominant manifestation of ADRs reported in surgical inpatients. When assessed for causality by using WHO-UMC scale, most of them were fulfilling the criteria for the category of possible, because it was common practice to give steroids and antihistamines for patients with suspected or proven ADR. Hence it was difficult to interpret the result of dechallenge and Rechallenge was not performed because of ethical reasons. The limitations of this study are- a) Predictability, preventability and financial burden incurred due to ADR's was not assessed. b) It was difficult to categorize ADR's according to Rawlins and Thompsons classification because of ambiguity associated with classification. Hence, we had more patients in type B category, which is contradictory to what is mentioned in textbooks and other research articles.

\section{CONCLUSION}

ADRs are one of the important causes of morbidity and mortality. The majority of them is not reported thinking that it is an expected adverse effect. A large portion of ADRs can be prevented if physicians choose drugs wisely and prescribe them rationally. In the market lot of Substandard, Spurious, falsely labelled, Falsified and Counterfeit (SSFFC) medications and fixed dose combinations (FDCs) are available, hence we require substantial evidence for using or banning any particular drug or FDC. One more drawback associated with ADRs is, not a single test can identify objectively about people who are at risk of developing an ADR. Hence, we require a method to monitor ADRs and provide the data which can be utilized to ban or to change the label of a particular drug. PvPI has initiated a process to gather scientific data on ADRs which can be utilized to prevent morbidity and mortality among Indian patients. Although this study contributes to only small data on ADRs, but it can be eye opener for many treating physicians. Further research in this area is needed, so that we can have a robust system to detect, analyze and prevent mortality related ADRs.

\section{ACKNOWLEDGEMENTS}

Authors would like to thank NCC-PvPI, IPC, Ministry of Health and Family Welfare for providing training and technical support to Amrita Institute of Medical Sciences, Kochi. Also like to acknowledge Dr. Prem Nair and Dr. Sanjeev K Singh for their constant encouragement and support.

\section{Funding: No funding sources}

Conflict of interest: None declared

Ethical approval: The study was approved by the Institutional Ethics Committee

\section{REFERENCES}

1. Edwards IR, Aronson JK. Adverse drug reactions: definitions, diagnosis, and management. Lancet. 2000;356:1255-9.

2. Sriram S, Ghasemi A, Ramasamy R, Devi M, Balasubramanian R, Ravi TK, et al. Prevalence of adverse drug reactions at a private tertiary care hospital in south India. J Res Med Sci. 2011 Jan;16(1):16-25.

3. Ramesh M, Pandit J, Parthasarathi G. Adverse drug reactions in a south Indian hospital: their severity and cost involved. Pharmacoepidemiol Drug Saf. 2003 Dec;12(8):687-92.

4. Agarwal RAS. Chapter-01 Key Definitions in Pharmacovigilance. In: Gupta SK, editor. Textbook of Pharmacovigilance [Internet]. Jaypee Brothers Pvt Ltd; 2011. Available at: http://dx.doi.org/10.5005/jp/books/11442_1

5. Organization WH. The use of the WHO-UMC system for standardized case causality assessment. Uppsala Uppsala Monit Cent [Internet]. 2005;(3):2-7. Available at: http://whoumc.org/Graphics/24734.pdf

6. Hartwig SC, Siegel J, Schneider PJ. Preventability and severity assessment in reporting adverse drug reactions. Am J Hosp Pharm. 1992;49:2229-32.

7. ATC/ DDD Index Available at: http://www.whocc.no/atc_ddd_index/

8. Mozzicato P. MedDRA: An overview of the medical dictionary for regulatory activities. Pharmaceut Med [Internet]. 2009;23(2):65-75. Available at: http://www.scopus.com/inward/record.url?eid=2s2.0-

70349086122\&partnerID=40\&md5=37cb675776f $86 \mathrm{e}$ $15 \mathrm{cb} 59411 \mathrm{~b} 9 \mathrm{bf} 2278 \mathrm{~b}$

9. Halkai K, Deshmukh S, Rao YV. An evaluation of adverse drug reactions at ADR monitoring center in tertiary care hospital. International Journal of Therapeutic Applications. 2016; 32:86-9.

10. Sutradhar SD, Ray D. A cross-sectional study of patterns of adverse drug reactions reported in the 
department of pharmacology of a tertiary care teaching hospital in North East India. International Journal of Comprehensive and Advanced Pharmacology. 2017;2(1):33-5.

11. Yadav D, Acharya RP. Incidence and severity associated with adverse drug reactions in surgery inpatients. J Pharm Sci Res. 2015;7(9):671-5.
Cite this article as: Khot A, Thomas TK, Savithri P, Rajalakshmi AN. Analysis of the pattern of ADR's reported to an ADR monitoring center in South India: a prospective study. Int J Basic Clin Pharmacol 2017;6:2477-81. 